\title{
A newly detected mutation of the RET protooncogene in exon 8 as a cause of multiple endocrine neoplasia type $2 \mathrm{~A}$
}

\author{
Sotirios Bethanis ${ }^{1}$, George Koutsodontis ${ }^{2}$, Theodosia Palouka ${ }^{1}$, Christos Avgoustis ${ }^{1}$, \\ Drakoulis Yannoukakos ${ }^{2}$, Thalia Bei ${ }^{2}$, Savas Papadopoulos ${ }^{3}$, Dimitrios Linos ${ }^{4}$, \\ Stylianos Tsagarakis ${ }^{1}$
}

${ }^{1}$ Department of Endocrinology, Athens Polyclinic, ${ }^{2}$ BioGenomica, Center for Genetic Research and Analysis, ${ }^{3}$ Department of Pathology, Hygeia Hospital, ${ }^{4}$ First Department of Surgery, Hygeia Hospital, Athens, Greece

\begin{abstract}
Multiple endocrine neoplasia type 2A (MEN2A) is a syndrome of familial neoplasias characterized by medullary thyroid carcinoma (MTC), pheochromocytoma and hyperplasia of the parathyroid glands. RET protooncogene mutations are responsible for MEN 2A. Mutations in exons 10 or 11 have been identified in more than 96\% of patients with MEN 2A. We herein report for the first time a patient with MEN $2 \mathrm{~A}$ harboring a mutation $\left(\mathrm{Gly}{ }^{533} \mathrm{Cys}\right.$ ) in exon 8 . A 66-year old male patient was referred to our department for bilateral adrenal nodules. The patient's family history was remarkable in that his mother had pheochromocytoma. Biochemical evaluation and findings of the magnetic resonance imaging of the adrenals were compatible with the diagnosis of bilateral pheochromocytomas. The patient underwent laparoscopic bilateral adrenalectomy and histological examination confirmed the preoperative diagnosis of pheochromocytoma. Absence of phenotypic characteristics of VHL or NF1 and elevated calcitonin levels both basal and post pentagastrin stimulation, raised the possibility of MEN 2A syndrome. Total thyroidectomy was performed and histological examination showed the presence of MTC. Direct sequencing of exon 8 from the patient's genomic DNA revealed the mutation c.1597G--> T (Gly533Cys). Although this missense point mutation has been associated with familial MTC (FMTC), to the best of our knowledge mutations in exon 8 have not previously been identified in patients with MEN 2A. In conclusion, in patients with clinical suspicion of MEN 2A syndrome, analysis of RET exon 8 should be considered when the routine evaluation of MEN 2A-associated mutations is negative. Furthermore, patients with FMTC and exon 8 mutations should also be screened for pheochromocytoma.
\end{abstract}

Key words: Multiple endocrine neoplasia type 2A, RET exon 8, RET mutations 


\section{INTRODUCTION}

Multiple endocrine neoplasia type 2A (MEN 2A) is a syndrome of familial neoplasias, transmitted in an autosomal dominant fashion and characterized by medullary thyroid carcinoma (MTC), pheochromocytoma and hyperplasia of the parathyroid glands. In MEN 2A about $90 \%$ of adult carriers of the mutated gene will develop MTC, $50 \%$ unilateral or bilateral pheochromocytoma and $20-30 \%$ parathyroid tumors. ${ }^{1}$

RET protooncogene mutations have been identified as the responsible molecular defect for MEN $2 \mathrm{~A} .^{2-4}$ The RET gene is located on 10q11.2, comprises 21 exons and encodes a single-pass transmembrane receptor tyrosine kinase..$^{5-7}$

Most MEN 2A mutations affect cysteines in the cysteine-rich extracellular portion of RET and result in constitutive activation of tyrosine kinase through the formation of disulfide-bonded RET homodimers (Table 1). In more than $96 \%$ of MEN $2 \mathrm{~A}$ families, single base pair mutations in exon 10 (codons 609, $611,618,620$ ) or exon 11 (codon 634) have been identified. ${ }^{2,3,8-10}$

We herein report a patient with MEN 2A harboring a mutation $\left(\mathrm{Gly}^{533} \mathrm{Cys}\right)$ in exon 8. This missense point mutation has recently been associated with familial MTC (FMTC), ${ }^{11,12}$ but mutations in exon 8 have not previously been identified in MEN 2A patients. Interestingly, our patient was presented with bilateral pheochromocytomas, whereas MTC was not clinically apparent.

\section{SUBJECTS AND METHODS}

\section{Patient's description}

A 66-year old Greek male patient was referred to the Endocrinology Department of the Athens Polyclinic for further assessment of bilateral adrenal nodules. The patient had a ten-year history of persistent hypertension under treatment with amilodipine without episodes of headache, sweating attacks or tachycardia. An ultrasound scan of the abdomen showed a right adrenal mass; subsequently, an adrenal computed tomography revealed bilateral adrenal nodules (right: maximum diameter $3.5 \mathrm{~cm}$; left: maximum diameter $2.5 \mathrm{~cm}$ ).
Table 1. RET mutations in MEN2A syndrome.

\begin{tabular}{|c|c|c|}
\hline Exon & Codon No & Amino acid substitution \\
\hline \multirow[t]{15}{*}{10} & 609 & Cys to Arg \\
\hline & & Cys to Tyr \\
\hline & 611 & Cys to Trp \\
\hline & & Cys to Tyr \\
\hline & 618 & Cys to Phe \\
\hline & & Cys to Ser \\
\hline & & Cys to Gly \\
\hline & & Cys to Arg \\
\hline & & Cys to Tyr \\
\hline & & Cys to Stop \\
\hline & 620 & Cys to Arg \\
\hline & & Cys to Tyr \\
\hline & & Cys to Phe \\
\hline & & Cys to Ser \\
\hline & & Cys to Gly \\
\hline \multirow[t]{8}{*}{11} & 630 & Cys to Phe \\
\hline & 634 & Cys to Arg \\
\hline & & Cys to Tyr \\
\hline & & Cys to Phe \\
\hline & & Cys to Ser \\
\hline & & Cys to Gly \\
\hline & & Cys to Tyr \\
\hline & 666 & Lys to Glu \\
\hline \multirow[t]{3}{*}{13} & 768 & Gly to Asp \\
\hline & 790 & Leu to Phe \\
\hline & 791 & Tyr to Phe \\
\hline \multirow[t]{2}{*}{14} & 804 & Val to Met \\
\hline & & Val to Leu \\
\hline 15 & 891 & Ser to Ala \\
\hline
\end{tabular}

The patient's family history was remarkable for the presence of pheochromocytoma in his mother and persistent hypertension in his mother's two sisters and one brother (Figure 1). On physical examination blood pressure of 180/120 $\mathrm{mm} \mathrm{Hg}$ was noted. There were no features of von Hippel-Lindau disease (VHL) or neurofibromatosis type 1 (NF1). Biochemical evaluation revealed elevated urinary normetanephrines $[1963 \mu \mathrm{g} / 24 \mathrm{~h}(\mathrm{NV}:<300)]$ and metanephrines excretion $[1270 \mu \mathrm{g} / 24 \mathrm{~h}(\mathrm{NV}:<350)]$. Metaiodobenzylguanidine scanning showed high uptake in the right 


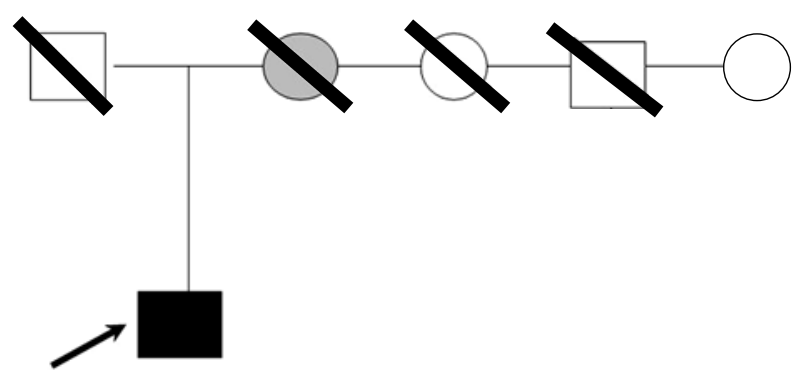

Figure 1. Genealogy of the patient's family. Patient's mother with histologically confirmed pheochromocytoma is colored grey. The mother's two sisters and one brother had persistent hypertension. An oblique line denotes deceased family members. The arrow denotes our patient (index case) with Gly ${ }^{533} \mathrm{Cys}$ mutation.

adrenal region. On magnetic resonance imaging both adrenal nodules appeared hyperintense to the liver on $\mathrm{T}_{2}$ weighted image (Figure 2). Phenoxybenzamine administration was initiated. Despite our recommendation for performance of bilateral adrenalectomy, following the patient's wish a laparoscopic right adrenalectomy was initially performed. Histological examination confirmed the preoperative diagnosis of pheochromocytoma (Figure 3a). Normetanephrines were in the normal range three months after surgery ( $68 \mu \mathrm{g} / 24 \mathrm{~h}$ ) but metanephrines' excretion was persistently elevated $[960 \mu \mathrm{g} / 24 \mathrm{~h}]$. The patient was referred

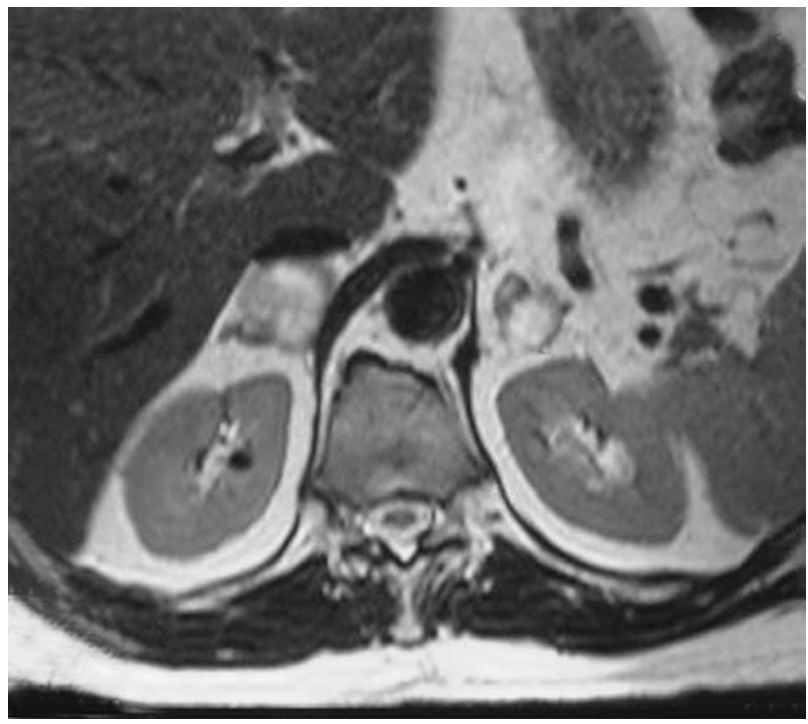

Figure 2. Magnetic resonance imaging of patient's bilateral adrenal nodules with markedly hyperintense appearance on $\mathrm{T}_{2^{-}}$ weighted image. for laparoscopic left adrenalectomy and histopathology confirmed the diagnosis of pheochromocytoma (Figure 3b).

The question of a familial pheochromocytoma syndrome such as MEN 2A, VHL or NF1 was raised based on the family history and the histologically confirmed diagnosis of bilateral pheochromocytomas. Absence of phenotypic characteristics of VHL or NF1 and elevated basal $[30.2 \mathrm{pg} / \mathrm{ml}(<26)]$ and stimulated by pentagastrin $(0.5 \mu \mathrm{g} / \mathrm{kg}$ during $3 \mathrm{~min})$ serum calcitonin levels $(455 \mathrm{pg} / \mathrm{ml})$ indicated the presence of MEN 2A syndrome. Total thyroidectomy was
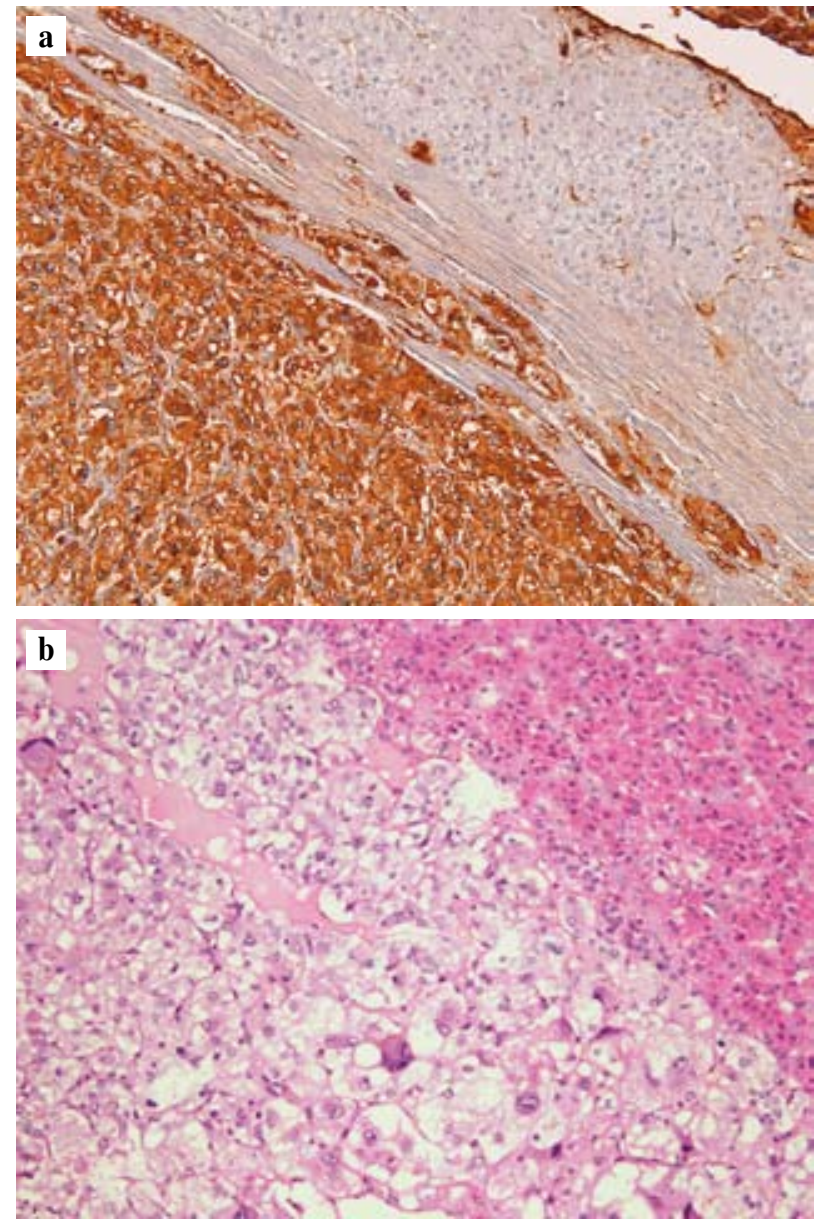

Figure 3. a. Immunohistochemically stained section of the right adrenal's pheochromocytoma (upper part: normal adrenal cortex; lower part tumor cells stained positive for chromogranin AMagnification x 100). b. Histological section with hematoxylin and eosin of the pheochromocytoma of the left adrenal (right: normal adrenal cortex; left: pheochromocytoma-Magnification $\mathrm{x}$ 100) 
performed and histological examination showed the presence of MTC. Genetic testing for the presence of a RET mutation was then recommended.

\section{DNA analysis and mutation detection}

Genomic DNA was prepared from peripheral blood samples collected on EDTA tubes according to standard protocols. The sequences of primers for exons $7,8,9,10,11,12,13,14,15,16,17,18,19,21$ were used and PCR protocols were obtained from previously published sources. ${ }^{11,13}$ Sequencing was performed in a genetic analyzer ABI3100.

\section{RESULTS}

The patient's genomic DNA was initially screened for RET mutations in exons 10,11, 13, 14, 15 and 16. As no molecular abnormalities were observed, analysis was extended to exons $7,8,9,12,17,18$, 19 and 21 of the RET gene in accordance with the guidelines for the diagnosis and therapy of MEN type 2 syndromes. ${ }^{1}$

Direct sequencing of exon 8 PCR products from genomic DNA revealed a $\mathrm{G}$ to $\mathrm{T}$ transversion in the heterozygote state at position 1597, which leads to a Gly to Cys amino-acid change at codon 533 (Figure 4). Since the above nucleotide change has been reported previously as the cause of FMTC in three large families, ${ }^{11,12}$ it was assumed that it is the cause of the disease in this patient too.

\section{DISCUSSION}

So far, mutations at RET exon 8 have been identified in patients with FMTC only. Pigny et al demonstrated the presence of a germline 9-bp duplication in RET exon 8 in all MTC patients of a large family with FMTC. The above duplication created an additional cysteine codon in the extracellular cysteine-rich domain of RET. ${ }^{13}$ Alvares Da Silva et al described a missence point mutation in exon 8 of the RET gene $(1597 \mathrm{G} \rightarrow \mathrm{T})$ that corresponded to a $\mathrm{Gly}{ }^{533}$ Cys substitution in 76 patients from a 6-generation Brazilian family with 229 subjects. ${ }^{11}$ Furthermore, Kaldrymides et al reported similar findings in two Greek families. ${ }^{12}$ Interestingly, none of the affected patients in these two studies with the Gly ${ }^{533}$ Cys missense mutations showed evidence of pheochromocytoma. We report

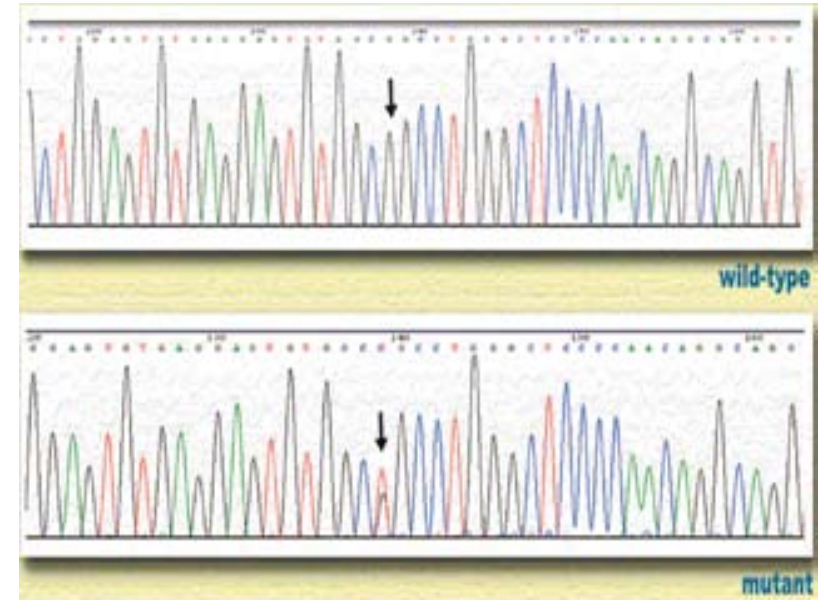

Figure 4. Direct sequencing of RET exon 8 showing $G>T$ transversion at position 1597 in our patient. The arrow in the lower sequence denotes the two overlapping peaks, indicative of the presence of two different nucleotides at that position in the sequence.

bilateral pheochromocytoma in a Greek patient with the missence point mutation in exon 8 of the RET gene $(1597 \mathrm{G} \rightarrow \mathrm{T})$, indicating that patients with this mutation also have a predisposition for MEN 2A. Previous studies have shown that Greek patients with MEN 2A and FMTC carry RET mutations similar to those of other ethnic groups. ${ }^{14,15}$ To the best of our knowledge, no molecular abnormalities of RET exon 8 have previously been reported in patients with MEN 2A syndrome. Therefore, this is the first report of a case of MEN 2A associated with the new RET mutation in exon 8 , codon 533 caused by a substitution of a glycine by a cysteine in the cysteine-rich extracellular portion of RET receptor.

MEN 2A carrier determination is one of the few examples of a genetic test that mandates a highly effective clinical intervention. ${ }^{16}$ Several significant observations emerge from the characterization of our patient with this novel RET mutation causing MEN 2A syndrome. First, while no clinical or biochemical evidence of pheochromocytoma was observed in the 76 patients with the Gly ${ }^{533}$ Cys substitution in RET exon 8 studied by Alvares Da Silva et al, ${ }^{11}$ bilateral pheochromocytoma was the presenting feature in our patient; secondly, a least aggressive form of MTC is documented by the fact that our patient had no evidence of clinically apparent MTC at the age of $66 \mathrm{yr}$ and no other family members died from 
causes related to MTC. It is interesting to note that all mutations that have previously been associated with pheochromocytoma demonstrated an earlier onset of MTC. ${ }^{17}$ It is understood that, due to the small number of patients with exon 8 mutations and the variable expression, it is not possible to calculate the penetrance of these mutations. Hence, follow-up of these cases is needed to ascertain the presence of tumors encountered in MEN 2A syndrome and their age-related progression. Moreover, as already pointed out by Moers et al, ${ }^{18}$ our case illustrates the difficulty in the distinction between FMTC and MEN 2 syndrome.

In conclusion, in patients with clinical suspicion of MEN 2A syndrome the analysis of RET exon 8 should be considered when routine evaluation of MEN 2Aassociated mutations is negative. Moreover, the case illustrates that, despite the absence of pheochromocytoma in individuals with exon 8 mutations thus far reported, pheochromocytoma should be considered in patients with this rare mutation.

\section{REFERENCES}

1. Brandi ML, Gagel RF, Angeli A, et al, 2001 Guidelines for diagnosis and therapy of MEN type 1 and type 2. J Clin Endocrinol Metab 86: 5658-5671.

2. Donis-Keller H, Dou S, Chi D, et al, 1993 Mutations in the RET proto-oncogene are associated with MEN 2A and FMTC Hum Mol Genet 2: 851-856.

3. Mulligan LM, Kwok JB, Healey CS, et al, 1993 Germline mutations of the RET proto-oncogene in multiple endocrine neoplasia type 2A. Nature 363: 458-460.

4. Quadro L, Panariello L, Salvatore D, et al, 1994 Frequent RET protooncogene mutations in multiple endocrine neoplasia type 2A. J Clin Endocrinol Metab 79: 590594.

5. Ishizaka Y, Itoh F, Tahira T, et al, 1989 Human ret protooncogene mapped to chromosome 10q11.2. Oncogene 4: 1519-1521.

6. Pachnis V, Mankoo B, Costantini F, 1993 Expression of the c-ret proto-oncogene during mouse embryogenesis. Development 119: 1005-1017.
7. Schuchardt A, D’Agati V, Larsson-Blomberg L, Costantini F, Pachnis V, 1994 Defects in the kidney and enteric nervous system of mice lacking the tyrosine kinase receptor Ret. Nature 367: 380-383.

8. Santoro M, Melillo RM, Carlomagno F, Vecchio G, Fusco A, 2004 Minireview: RET: normal and abnormal functions. Endocrinology 145: 5448-5451.

9. Mulligan LM, Eng C, Attie T, et al, 1994 Diverse phenotypes associated with exon 10 mutations of the RET proto-oncogene. Hum Mol Genet 3: 2163-2167.

10. de Groot JW, Links TP, Plukker JT, Lips CJ, Hofstra $\mathrm{RM}, 2006 \mathrm{RET}$ as a diagnostic and Therapeutic target in sporadic and hereditary endocrine tumors. Endocr Rev 27: 535-560.

11. Alvares Da Silva AM, Maciel RM, Da Silva MR, Toledo SR, De Carvalho MB, Cerutti JM, 2003 A novel germline point mutation in RET exon $8(\mathrm{Gly}(533) \mathrm{Cys})$ in a large kindred with familial medullary thyroid carcinoma. J Clin Endocrinol Metab 88: 5438-5443.

12. Kaldrymides P, Mytakidis N, Anagnostopoulos A, et al, 2006 A rare RET gene exon 8 mutation is found in two Greek kindreds with familial medullary thyroid carcinoma: implications for screening. Clin Endocrinol 64: 561-566.

13. Pigny P, Bauters C, Wemeau JL, et al, 1999 A novel 9-base pair duplication in RET exon 8 in familial medullary thyroid carcinoma J Clin Endocrinol Metab 84: 1700-1704.

14. Alevizaki M, 2006 Medullary thyroid carcinoma: Clinical presentation and diagnosis. In: Hercules Vainas (ed), Thyroid Cancer, Thessaloniki; pp, 395-411.

15. Karga HJ, Karayianni MK, Linos DA, Tseleni SC, Karaiskos KD, Papapetrou PD, 1998 Germ line mutations analysis in families with multiple endocrine neoplasia type $2 \mathrm{~A}$ or familial medullary thyroid carcinoma. Eur J Endocrinol 139: 410-415.

16. Polychronakos C, 2003 Genetic testing in Clinical Endocrinology. Hormones (Athens) 2: 201-210.

17. Jimenez C, Habra MA, Huang SC, et al, 2004 Pheochromocytoma and medullary thyroid carcinoma: a new genotype-phenotype correlation of the RET protooncogene 891 germline mutation J Clin Endocrinol Metab 89: 4142-4145.

18. Moers AMJ, Landsvater RM, Schaap C, et al, 1996 Familial medullary thyroid carcinoma: Not a distinct entity? Genotype-phenotype correlation in a large family. Am J Med 101: 634-641. 